Mr Nenko Brkljač, major, dipl. inž. Tehnički opitni centar

Beograd

\section{KVALITET U FUNKCIJI MAKSIMIZACIJE BORBENE GOTOVOSTI}

UDC: $005.6: 623.483$

Rezime:

U sistemu opremanja Vojske sredstvima NVO sistemu menadžmenta kvalitetom mora biti podređena čitava organizacija, kao i opredeljenje najvišeg rukovodstva $i$ zaposlenih. Neophodni preduslovi za uspostavljanje efikasnog (racionalnog) sistema sadržani su u primeni savremenih pristupa obezbeđenju kvaliteta, koji isključuju eklektički pristup pitanju „,dokumentovanosti“, koja je samo jedan u nizu velikog broja elemenata (složenih procesa) za obezbeđenje kvaliteta, koje treba oživotvoriti da bi se kreirala, kao krajnji rezultat, maksimalna borbena gotovost.

Ključne reči: kvalitet, sistem menadžmenta kvalitetom, procesni pristup, sistem opremanja Vojske, odlučivanje.

\title{
QUALITY IN THE FUNCTION OF COMBAT READINESS MAXIMIZATION
}

Summary:

In order to achieve top combat readiness, it is necessary that military system provision top management recognize need for quality management system establishment based on „process approach“. Whole organization and orientation of top management and employee must be subjected to quality management system. For efficient (rational) quality management system consolidation it is necessary to assure contemporary approach quality assurance, excluding eclectic approach to ,documentation“. „Documentation“ is only one condition among many difficult elements (process) for quality assurance which is necessary to create top combat readiness, as a final result.

Key words: quality management system, evaluation admission, military system provision, decision making.

\section{Uvod}

Aktuelni pristupi u mnogim organizacijama „uspostavljanju sistema menadžmenta kvalitetom" su različiti, i za sve je karakterističan eklektički pristup pitanju kvaliteta. U dosadašnjoj praksi, iz ugla organizacije rada na uspostavljanju sistema menadžmenta kvalitetom, prisutni su različiti pristupi, koji se mogu svrstati u četiri karakteristične grupe. Radi lakše ilustracije (slika 1) pomenutih gru- pa koriste se skupovi koji označavaju funkcionalni skup ,poslovnog sistema“ ${ }^{\text {“1 }}$ (veći krug) i funkcionalni skup za obezbeđenje kvaliteta (manji krug).

Slika 1a ilustruje pristup (u organizacionom smislu) na taj način što se $u$ okviru organizacije formira ,radna grupa“ čiji je zadatak ,uspostavljanje sistema menadžmenta kvalitetom" po seriji standarda JUS ISO 9001. Svoje aktivno-

\footnotetext{
Termin „poslovni sistem“ koristi se kao termin za di-
} namički izraz organizacije. 
sti ovaj skup ljudi, uglavnom, orijentiše na eksterno obezbeđenje kvaliteta u smislu „neophodne papirologije“, koja treba da omogući organizaciji sticanje sertifikata i statusa „priznati isporučilac“. Pri izradi dokumentacione osnove za sticanje pomenutog statusa, uglavnom se najčešće koriste „etalon“ dokumenti, koji se sa određenim izmenama usvajaju kao matični dokumenti organizacije.

Slika $1 b$ ilustruje pristup kada organizacija plaća „konsalting usluge“, gde za znatne sume novca dobija veliki broj dokumenata koji su „prilagođeni potrebama“ konkretne organizacije kroz izmene uglavnom generalija na dokumentima (naziv organizacije, znak, oznaka i slično).

Slika 1c ilustruje stanje između 1a i 1b, a u osnovi se, kao i kod la i 1b, javljaju isti nedostaci u odnosu na suštinsku dinamičku prirodu organizacije. Naime, velikim brojem dokumenata, koji nastaju na opisan način, ne može se rešiti u osnovi kompleksna funkcionalna priroda organizacionog sistema, pa ni sistema opremanja Vojske. Pored toga, osoblje koje je neposredno angažovano na projektu ,uspostavljanja sistema menadžmenta kvalitetom“ u većini organizacija dobija ,specijalni status“, što doprinosi većem ,organizacionom sektaštvu" i produbljivanju otpora prema promenama. „Dokumentovanost" koja nastaje na osnovu tipiziranih dokumenata proizvodi velike otpore kod ljudi koji ta dokumenta treba da uvode u primenu, a koja često i ne odslikavaju realnu funkcionalnu prirodu procesa koje opisuju.

Slika 1d ilustruje značaj primene ,procesnog pristupa ${ }^{\text {“2 }}$ u sistemu oprema-

${ }^{2}$ Definicija procesnog pristupa prema standardu JUS ISO 9000:2001: „Željeni rezultat se može efikasnije ostvariti ako se menadžment odgovarajućim aktivnostima i resursima ostvaruje kao proces".
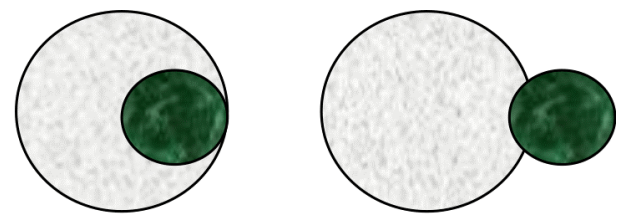

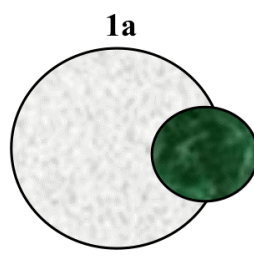

$1 \mathbf{c}$

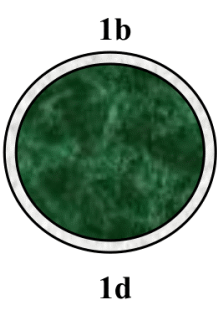

Slika 1 nja Vojske. Procesni pristup integrisan sa sistemskim pristupom menadžmentu ${ }^{3}$ jedinstven je po tome što usmerava sistem opremanja Vojske ka kreiranju maksimalne borbene gotovosti posredstvom razvoja i obezbeđenja kvaliteta sredstava NVO.

\section{Obezbeđenje kvaliteta sredstava NVO}

Neophodno je odrediti koji je, za sistem opremanja Vojske, najviši hijerarhijski princip iz kojeg se izvode svi drugi principi i stavovi. Uzimajući u obzir činjenicu da je glavni generator zbivanja u sistemu opremanja Vojske sredstvo NVO, može se zaključiti da je najviši hijerarhijski princip „kreiranje maksimalne borbene gotovosti“, što se ostvaruje kvalitetom sredstava na nivou konkurentnosti na svetskom tržištu naoružanja i vojne opreme. Uzimajući ovaj princip za osnovu, neophodno je logikom dekompozicije projektovati jedinstven ,procesni model" sistema opremanja Vojske.

Dakle, ma kakva bila ,dokumentovanost" u sistemu opremanja Vojske, ona

${ }^{3}$ Definicija sistemskog pristupa menadžmentu prema standardu JUS ISO 9000:2001: „Identifikovanje i razumevanje nekog sistema međusobno povezanih procesa i menadžment tim sistemom doprinose efektivnosti i efikasnosti organizacije u ostvarivanju njenih ciljeva. 
sama ne obezbeđuje kretanje sistema $\mathrm{u}$ željenom smeru, čime se njena uloga ne dovodi u pitanje, već ističe neophodnost uključivanja u ta ostvarenja mnoštvo drugih složenih procesa.

Svodni podsistemi koji generišu kvalitet sredstava NVO prikazani su na slici 2.

$\mathrm{U}$ različitim fazama kvalitet sredstva NVO varira, tj. sredstvo NVO prolazi kroz određene faze, a svaka faza postavlja pred sistem opremanja Vojske različite izazove. Bez obzira na to u kojoj se fazi sredstvo NVO nalazi (razvoj, proizvodnja, utvrđivanje usaglašenosti, korišćenje, remont) kvalitet je generator njegove vrednosti. Faza je značajna iz ugla odluke najvišeg rukovodstva u sistemu opremanja Vojske u pogledu izbora i primene različitih strategija (izbor

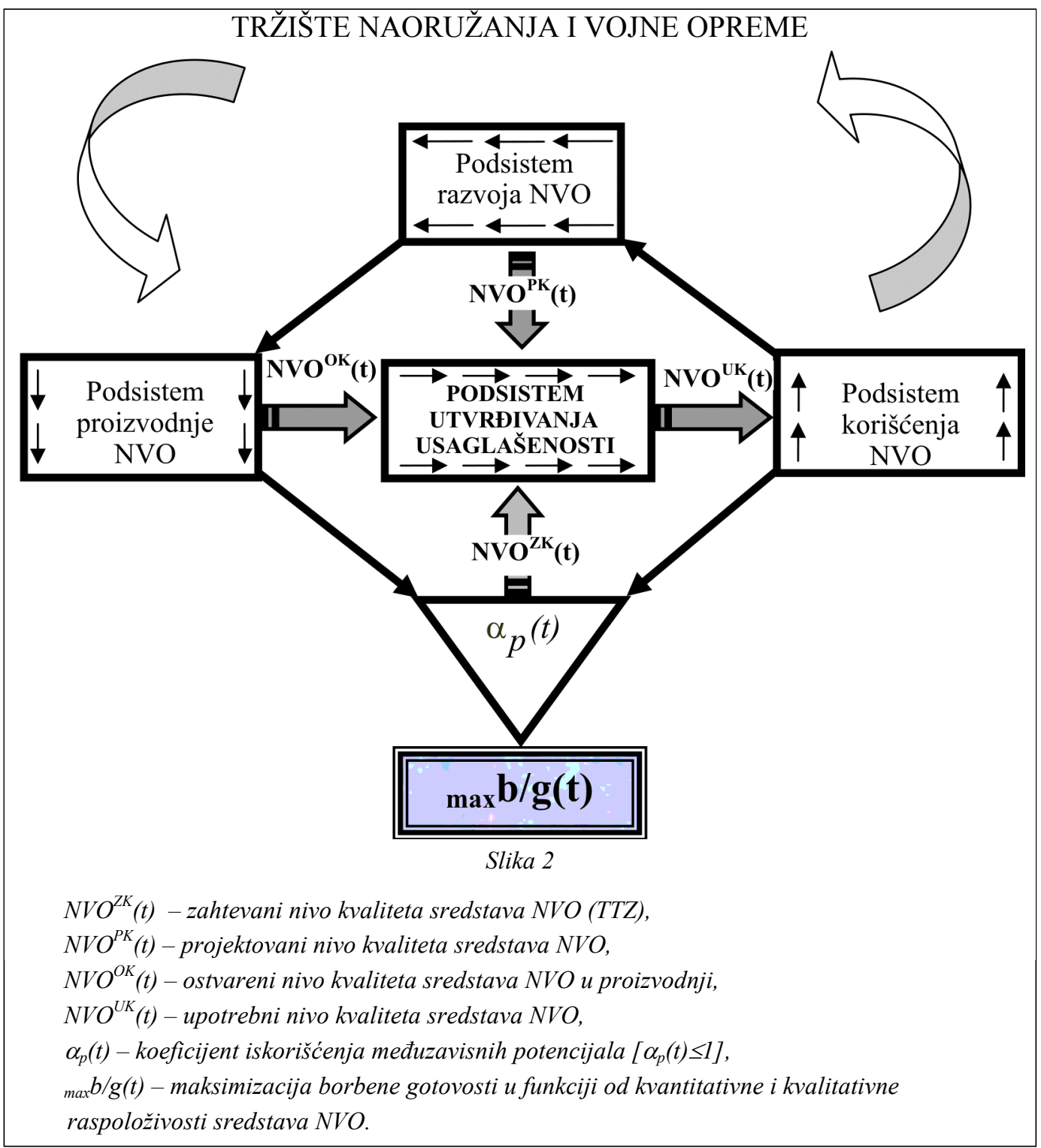


modela opremanja Vojske - sopstveni razvoj ili nabavka gotovog sredstva NVO sa tržišta; model finansiranja, model podugovaranja određenih aktivnosti, itd.) dok je strategija kvaliteta kontinualna i permanentna.

Jedan od ciljeva primene, ,procesnog pristupa“ jeste postizanje ,sistemske konzistentnosti“ $u$ funkcionisanju sistema opremanja Vojske koja će omogućiti maksimizaciju koeficijenta iskorišćenja međuzavisnih potencijala $-\alpha_{\mathrm{p}}(\mathrm{t})$, a samim tim obezbediti uslove za ostvarenje maksimalne borbene gotovosti - max $\mathrm{b} / \mathrm{g}(\mathrm{t})$ pri datim uslovima ograničenja.

U praksi postoje najmanje četiri stanja kvaliteta sredstva NVO: projektovani kvalitet, ostvareni kvalitet, upotrebni kvalitet (fazna stanja) i stanje željenog kvaliteta (zahtevani kvalitet). Kvalitet sredstva NVO mora da zadovolji izražene potrebe Vojske (TTZ) i potrebe koje se podrazumevaju.

Ako se posmatra stanje kvaliteta sredstava NVO (slika 2), može se zaključiti da je integralni cilj sistema opremanja Vojske ostvarenje uravnoteženja naznačenih faznih stanja kvaliteta sredstava NVO.

Uslovi za optimizaciju (racionalizaciju) u sistemu opremanja Vojske obezbeđeni su, iz ugla kvaliteta proizvoda, ako se postignu ekvivalenti navedeni na slici 2 .

Slika 3 ilustruje ekvivalente koji jedino mogu da se ostvaruju primenom „procesnog pristupa“ $u$ sistemu opremanja Vojske. To je preduslov da koeficijent iskorišćenja međuzavisnih potencijala teži svom maksimumu (jedinici) $\left[\alpha_{\mathrm{p}}(\mathrm{t}) \rightarrow 1\right]$. Iz toga se može zaključiti da maksimalna borbena gotovost zavisi od kvaliteta sredstava NVO, odnosno koeficijenta iskorišćenja međuzavisnih potencijala.

Prirodni uslovi sa slike 2 i 3 determinišu sledeću zavisnost:

$$
\begin{aligned}
& { }_{N V O} Q_{o p t}^{K K}(t) \cong \oint\left[K A P_{S O V}(t) ; T_{N V O}(t)\right] \equiv \\
& \equiv \alpha_{p}(t) \cdot{ }_{N V O} Q^{* K}(t)
\end{aligned}
$$

gde je:

${ }_{N V O} Q_{o p t}^{K K}(t)$ - optimalna količina sredstava NVO u kvantitativnom i kvalitativnom smislu koja obezbeđuje ${ }_{\text {max }} b / g(t) \mathrm{u}$ datim prirodnim uslovima; $K A P_{S O V}(t)$ - kvalitet angažovanih potencijala u sistemu opremanja Vojske;

$T_{N V O}(\mathrm{t})$ - raspoloživost sredstava NVO na tržištu naoružanja i vojne opreme;

$\alpha_{p}(t)$ - koeficijent iskorišćenja međuzavisnih potencijala $\left[\alpha_{\mathrm{p}}(\mathrm{t}) \leq 1\right] \mathrm{i}$

${ }_{N V O} Q^{* K}(\mathrm{t})$ - maksimalno moguće ostvarenje.

Iz navedenog sledi da maksimalna borbena gotovost zavisi od kvaliteta sredstava NVO, kvaliteta sistema menadžmenta, kvaliteta potencijala u sistemu opremanja Vojske, odnosno od koeficijenta iskorišćenja međuzavisnih potencijala.

$$
{ }_{\max } b / g(t) \equiv \oint\left[{ }_{N V O} Q_{o p t}^{K K}(t) ;_{\max } \alpha_{p}(t)\right]
$$

Ako se sa $\zeta_{\mathrm{i}}(\mathrm{t})$ označi koeficijent efikasnosti sistema opremanja Vojske, sa aspekta obezbeđenja zahtevanog kvaliteta sredstava NVO (TTZ), tada je:

$$
\zeta_{i}(t)=N V O^{O K}(t) / N V O^{Z K}(t) ;\left(\zeta_{i} \rightarrow 1\right)
$$

Veličina ovog koeficijenta (kao vremenske funkcije) ima značajan uticaj na maksimizaciju borbene gotovosti. Trajna orijentacija sistema menadžmenta kvalitetom u sistemu opremanja Vojske je da obezbeđuje kontinualan priraštaj optimalnih količina sredstava NVO u kvantitativnom i kvalitativnom smislu, uz minimizaciju ukupnih troškova. Ova orijentacija ilustrovana je na slici 4 . 


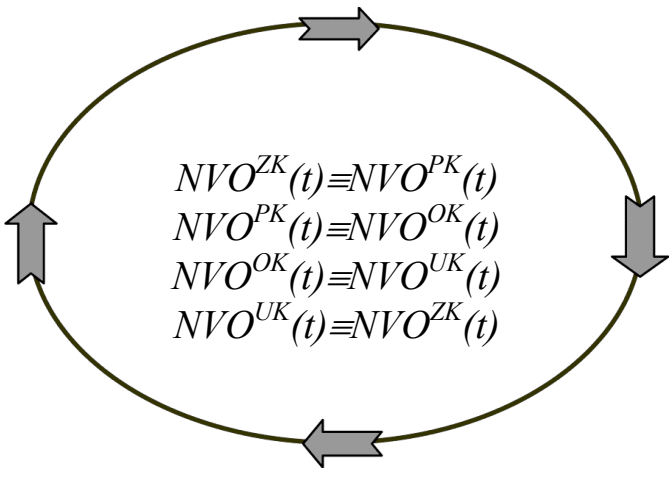

Slika 3

Efikasnost (racionalnost) sistema opremanja Vojske može se uspešno ostvarivati samo ako se potpuno integrišu elementi sistema primenom ,procesnog pristupa" $i$ ako se primenjuju savremene - formalizovane metode „odlučivanja“.

Jedan značajan proces $\mathrm{u}$,,procesnom modelu“ sistema opremanja Voj- ske jeste „proces odlučivanja“. Karakterističan izlaz iz ovog procesa je odluka da li sredstvo NVO treba razvijati potencijalima sistema opremanja Vojske i namenske industrije ili ga kupovati kao gotovo sredstvo NVO sa tržišta naoružanja i vojne opreme. Granične vrednosti elemenata za donošenje ovih odluka ilustrovane su na slici 5 (kvalitet, kvantitet, nacionalni značaj...).

Maksimizacija borbene gotovosti, kao funkcija kvaliteta sredstava NVO, može se uspešno ostvarivati samo ako se potpuno integrišu elementi sistema opremanja Vojske. Za tu integraciju neophodno je oživotvoriti mnoge procese (kao što je proces odlučivanja), preko kojih će se sistem opremanja Vojske usmeravati na postizanje maksimalne borbene gotovosti.

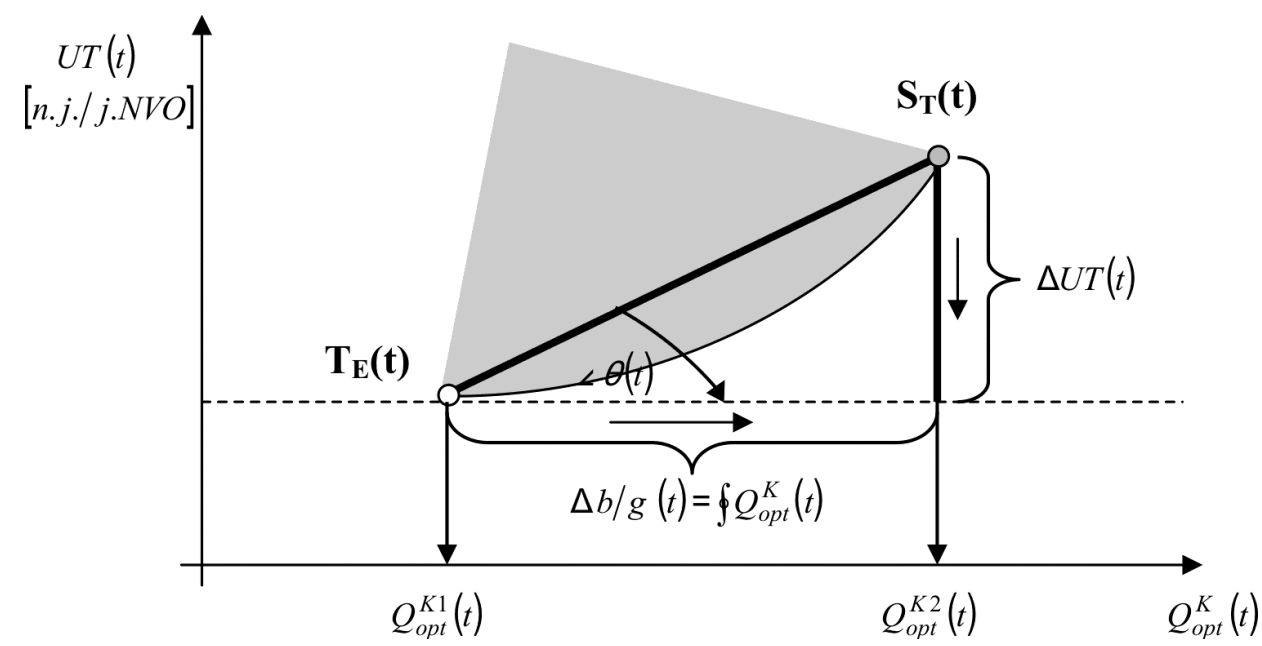

Slika 4

$T_{E}(t)$ - polazna tačka efektivnosti sistema opremanja Vojske,

$S_{T}(t)$ - stacionarna tačka u kojoj se preispituje odluka alternativa: sopstveni razvoj ili nabavka sa tržišta ,gotovih sredstava NVO",

$\Delta b / g(t)=\oint \mathrm{Q}_{\mathrm{opt}}^{\mathrm{K}}(\mathrm{t})$ - priraštaj borbene gotovosti u funkciji unapređenja karakteristika $i$ svojstava sredstava NVO,

$\Delta U T(t)$ - priraštaj ukupnih troškova po osnovu unapređenja i održavanja kvaliteta sredstava NVO, $\angle \theta(t)$ - ugao koji određuje stacionarnu tačku - funkcionalni cilj je da tg $\theta \rightarrow O$. 


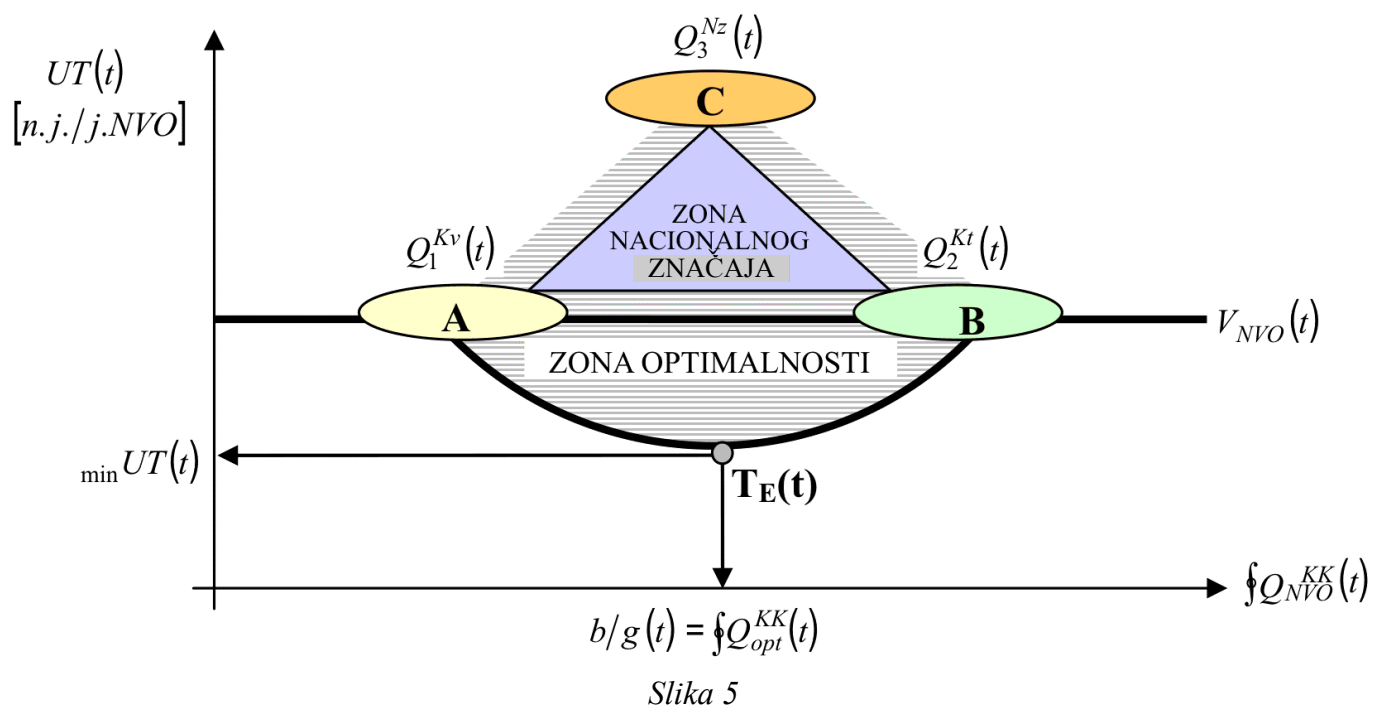

$Q_{1}^{K v}(t)(A)$ - granična vrednost za sredstvo NVO sa aspekta mogućnosti obezbeđenja kvaliteta putem sopstvenog razvoja ili kupovinom na tržištu NVO;

$Q_{2}{ }^{K t}(t)(B)$ - granična vrednost za sredstvo NVO iz kvantitativnog aspekta u odnosu na potrebne količine i racionalnost sopstvenog razvoja i proizvodnje tih količina;

$Q_{3}{ }^{N z}(t)(C)$ - granična vrednost za sredstvo NVO od nacionalnog značaja za koje su opravdani potencijalno veći ukupni troškovi;

$V_{N V O}(t)$ - vrednost sredstava NVO u funkciji: cene (nabavne cene), kvaliteta (upotrebne

vrednosti) i njegovog nacionalnog značaja.

\section{Zaključak}

U prošlosti se često bezuspešno pokušavalo da se savremenim informacionim sistemom reši suštinska funkcionalna priroda poslovnog sistema. Isto tako, ,dokumentovanost" $\mathrm{u}$ organizaciji ne rešava funkcionalnu prirodu te organizacije. Ona je značajan element obezbeđenja kvaliteta sredstava NVO, ali se cilj ne postiže isključivo preko nje, jer je neophodno oživotvoriti i niz drugih procesa i permanentno raditi na kontinuitetu njihovog uticaja na efikasnost (racionalnost) funkcionisanja sistema opremanja Vojske.

Ostvarenja maksimalne borbene gotovosti i kvaliteta sredstava NVO na savremenom nivou su dva pola jednog jedinstva. Za postizanje ovih ostvarenja neophodno je uspostaviti sistem menadžmenta kvalitetom u sistemu opremanja Vojske, koji će biti baziran na određenom procesnom modelu. Osnovna karakteristika procesnog modela sistema opremanja Vojske jeste da orijentiše potencijale u željenom pravcu ostvarenja. Na taj način obezbediće se integracija svih elemenata (organizacionih entiteta) $u$ sistemu opremanja Vojske.

Literatura:

[1] Mitrović, Ž. i dr.: Kako uvesti sistem kvaliteta, Kultura, Beograd, 1999.

[2] Mitrović, Ž.: Sistem integralne kontrole kvaliteta, Sloboda, Beograd, 1989.

[3] JUS ISO 9001:2001 - Sistemi menadžmenta kvalitetom Zahtevi, Zavod za standardizaciju, 2001.

[4] Brkljač, N.: Magistarski rad Razvoj sistemskog pristupa obezbeđenju kvaliteta integrisanog u model poslovnog sistema za ostvarenje maksimalne dobiti, Mašinski fakultet, Beograd, 1997. 